cytoplasm. In places the interstitial fibrosis projected into the tubules of the ductuli efferentes testis and epididymis as broad obstructing papillary structures. Haemosiderin deposition was not a feature.

The testis showed extensive, focal tubular atrophy and fibrosis with the rest of the tubules showing mild hypospermatogenesis. The body and tail of the epididymis showed extremely dilated epididymal tubules containing proteinaceous material and occasional spermatozoa.

\section{Discussion}

Chronic renal failure may produce hyperoxalaemia and secondary oxalosis due to decreased oxalate excretion with the tissue deposition (oxalosis) typically occurring within the kidney, although other organs may also be involved. ${ }^{1-3}$ Furthermore, deposition of calcium oxalate crystals within the rete testis and ductuli efferentes of patients with chronic renal failure has been described under the descriptive notation of acquired cystic transformation of the rete testis. ${ }^{4}$ Although showing cystic dilatation of the rete testis, this case differs in several respects including the clinical presentation with a palpable, intrascrotal lesion, haematospermia (which was cured by surgery), and a small associated hydrocele. Also, the histological involvement was more extensive producing prominent epididymal oxalosis and epididymal spermatic granuloma formation. Direct damage to the epididymal tubular epithelium and basement membrane, with or without tubular obstruction and distension caused by interstitial fibrosis, are mechanisms for spermatic granuloma formation. To the best of our knowledge, the combination of calcium oxalosis and spermatic granulomas of the epididymis has not been reported before.

We thank Dr Alan Curry for the photomicrographs and Mrs Linda Garstang for excellent secretarial assistance.

1 Salyer WR, Keren D. Oxalosis as a complication of chronic renal failure. Kidney Int 1973;4:61-6.

2 Cuppage FE, Chonko AM. Urate and uric acid nephropathy, cystinosis and oxalosis. In: Tisher CC, Brenner BM, eds. Renal pathology. Philadelphia: JB Lippincott, BM, eds. Renal
1989:1351-7.

3 Chaplin AJ. Histopathological occurrence and characterisation of calcium oxalate: a review. $\mathcal{F}$ Clin Pathol 1977; 30:800-11.

4 Nistal M, Santamaria L, Paniagua R. Acquired cystic transformation of the rete testis secondary to renal failure. Hum Pathol 1989;20:1065-70.

\title{
Polycythaemia rubra vera transforming to acute lymphoblastic leukaemia with a common immunophenotype
}

\author{
J R Neilson, W N Patton, M D Williams, E E Mayne, B J Boughton
}

\author{
Department of \\ Haematology, Queen \\ Elizabeth Hospital, \\ Birmingham \\ J R Neilson \\ W N Patton \\ M D Williams \\ B J Boughton \\ Department of \\ Haematology, Royal \\ Victoria Hospital, \\ Belfast \\ E E Mayne \\ Correspondence to: \\ Dr J R Neilson, Department \\ of Haematology, \\ of Haematology, \\ Birmingham Heartlands
Hospital, Bordesley Green \\ East, Birmingham. \\ Accepted for publication \\ 25 November 1993
}

\begin{abstract}
Lymphoblastic transformation of polycythaemia rubra vera is an extremely rare phenomenon. A case of a 76 year old man with polycythaemia rubra vera who developed acute lymphoblastic leukaemia (ALL) 16 years after his initial diagnosis is reported. Membrane markers showed a CD10 positive (common ALL) immunophenotype. To our knowledge this association has not been previously recorded. The rare occurrence of ALL in polycythaemia rubra vera may indicate that in a minority of patients clonal expansion of an abnormal pluripotent haemopoetic stem cell is responsible for the polycythaemia rubra vera disease phenotype.
\end{abstract}

\section{(F Clin Pathol 1994;47:471-472)}

The transformation of polycythaemia rubra vera to myelofibrosis or acute myeloblastic leukaemia is well recognised but the transfor- mation of polycythaemia rubra vera to acute lymphoblastic leukaemia (ALL) is an extremely rare phenomenon. We report a case of polycythaemia rubra vera who transformed into ALL with a CD10 positive immunophenotype, to our knowledge, an association not previously recorded.

\section{Case report}

A 76 year old man presented with polycythaemia rubra vera in 1974 . His haemoglobin concentration was $230 \mathrm{~g} / \mathrm{l}$, white cell count $11.2 \times 10^{9} / 1$, and platelet count $260 \times$ $10^{\circ} / 1$. Splenomegaly $(3 \mathrm{~cm})$ was present and his red cell mass was raised at $60.6 \mathrm{ml} / \mathrm{kg}$. He was initially treated with venesection and aspirin. Intermittent low dose busulphan treatment was started in 1979 for increasing splenomegaly. Treatment with intermittent venesection and low dose busulphan was continued until the development of deteriorating pancytopenia (haemoglobin concentration 72 $\mathrm{g} / \mathrm{l}$, white cell count $2.5 \times 10^{9} / 1$, platelet count 
$26 \times 10^{9} / 1$ ), and $12 \mathrm{~cm}$ splenomegaly in October 1990.

At this stage a bone marrow aspirate showed $98 \%$ infiltration with blast cells. These cells showed coarse granular positivity with periodic acid Schiff and were negative for sudan black and both chloroacetate and butyrate esterases. Immunophenotypic analysis of bone marrow mononuclear cells by fluorescence activated cell sorter showed strong positivity for CD38 (99\%), HLA-DR (76\%), CD19 (63\%), and CD10 (49\%) antigens but staining for surface immunoglobulin was negative and the expression of CD23 (2\%), CD3 (2\%), CD5 (0\%), CD7 (14\%), CD11b (11\%), CD13 (4\%), CD13 (4\%), CD33 (7\%), and CD14 (6\%) antigens were all at low frequency. These features are consistent with common ALL. Bone marrow cytogenetic analysis showed a normal male karyotype. The patient was treated with vincristine and prednisolone and when a bone marrow aspirate at 14 days showed residual leukaemia, cytarabine was added to his treatment. The patient died of infection 26 days after starting induction treatment.

\section{Discussion}

There have been four previous reports of lymphoblastic transformation occurring in adults with polycythaemia rubra vera. Two of these reports have described "null" ALL transformation, ${ }^{12}$ one $T$ cell ALL transformation, and one case was unclassified. ${ }^{3}$ All of these cases had received previous treatment with radioactive phosphorus or alkylating agents. All of the patients described died shortly after transformation to ALL which occurred five to 16 years after initial diagnosis of polycythaemia rubra vera. Other reports describe polycythaemia rubra vera in a child in remission from ALL who subsequently relapsed with $A L L^{4}$ and surface immunoglobulin positive lymphoblastic malignancy in an adult with polycythaemia rubra vera.

The association of polycythaemia rubra vera and lymphoproliferative disorders is of interest. Others have reviewed the association between polycythaemia rubra vera and chronic lymphocytic leukaemia and nonHodgkin's lymphoma and speculated on the evolution of lymphoid malignancies in polycythaemia rubra vera. ${ }^{15}$ The extreme rarity of lymphoblastic transformation may indicate that in most cases the target cell is a pluripotent myeloid committed stem cell. A recent review of leukaemic transformation (all myeloid) in polycythaemia rubra vera came to this conclusion. ${ }^{6}$

The very occasional occurrence of lymphoblastic transformation in polycythaemia rubra vera may indicate that in a small proportion of cases clonal expansion of an abnormal uncommitted pluripotent haemopoetic stem cell results in the polycythaemia rubra vera phenotype. Alternatively, ALL may be coincidental.

1 Braich TA, Grogan TM, Hicks MJ, Greenberg BR Terminal lymphoblastic transformation in polyTerminal lymphoblastic transformation
cythaemia vera. $A m \mathcal{F} M e d$ 1986;80:304-6.

cythaemia vera. Am $\mathcal{F}$ Med 1986;80:304-6.
Aichison R, Black AJ, Greaves MF. Polycythaemia rubra Aichison R, Black AJ, Greaves MF. Polycythaemia rubra vera transforming to acute lym
Clin Lab Haematol 1987;9:201-4.

3 Hoffman R, Estren S, Kopel S, Marks SM, McCaffre RP. Lymphoblastic-like leukaemia transformation of polycythaemia vera. Ann Intern Med 1978;89:71.

4 Hann HL, Feta RS, Rosenstock JG, Cifuentes E Polycythaemia vera in a child with acute lymphoblastic leukaemia. Cancer 1979;43:1862-5.

5 Anastasi J, Pettenati MJ, Le Beau MM, Kwaan HC, Weil SC. Acute lymphoblastic leukaemia in a patient with longstanding polycythaemia vera: Cytogenetic analysis reveals two distinct clones. Am f Hematol 1988;29: reveals

6 Hernandez JM, Orfao A, Gonzalez M, et al. Immunophenotypic characterisation of acute leukaemia after Polycythaemia vera. $\mathcal{f}$ Clin Pathol 1993;46:668-71. 